\title{
CIRCADIAN RHYTHM OF CORE BODY TEMPERATURE (PART II): HYPERBARIC ENVIRONMENT INFLUENCE ON CIRCADIAN RHYTHM OF CORE BODY TEMPERATURE
}

\author{
Joanna Słomko $^{1)}$, Mariusz Kozakiewicz ${ }^{2)}$, Jacek J. Klawe ${ }^{1)}$, Małgorzata Tafil-Klawe ${ }^{3)}$, Piotr Siermontowski ${ }^{4)}$, \\ Paweł Zalewski ${ }^{1)}$ \\ 1) Chair of Hygiene, Epidemiology and Ergonomics, CM UMK, Bydgoszcz, Poland \\ 2) Chair and Department of Chemistry of Foodstuffs, CM UMK, Bydgoszcz, Poland \\ ${ }^{3)}$ Department of Human Physiology, CM UMK, Bydgoszcz, Poland \\ 4) Naval and Hyperbaric Medicine Department, WIM, Gdynia, Poland
}

\section{ABSTRACT}

The aim of this study was to analyse dynamic fluctuations in the circadian rhythm of the core body temperature in healthy adults exposed to conditions in a hyperbaric chamber, using fully objective-telemetric measurement methods. The study group consisted of 13 healthy males (age $32 \pm 6.4$ years, height $1.85 \pm 0.1 \mathrm{~m}$, body weight $84.00 \pm 6.3 \mathrm{~kg}$; BMl $24.7 \pm 1.2 \mathrm{~kg} / \mathrm{m}^{2}$ ). The core body temperature (CBT) was measured with the Vital Sense telemetry system. The volunteers were placed in a hyperbaric chamber, exposed to compression of $400 \mathrm{kPa}$, with the exposure plateau of approx. 30 minutes, followed by gradual decompression. The mean core temperature was $36.71^{\circ} \mathrm{C}$ when registered within 10 minutes before the exposure, $37.20^{\circ} \mathrm{C}$ during the exposure, $37.27^{\circ} \mathrm{C}$ one hour after the exposure, $37.36^{\circ} \mathrm{C} 2$ hours after the exposure, and $37.42^{\circ} \mathrm{C}$ three hours after the exposure. The conducted observations show that onehour stay in a hyperbaric chamber at a depth of $30 \mathrm{~m}$ results in an increase in the body temperature, particularly significant after the exposure ends, and maintained for at least 3 hours after the exposure.

Key words: circadian rhythm, body temperature, hyperbaric.

\section{ARTICLE INFO}

PolHypRes 2016 Vol. 57 Issue 4 pp. 19 - 28

ISSN: 1734-7009 elSSN: 2084-0535

DOI: $10.1515 /$ phr-2016-0022

Pages: 10 , figures: 3 , tables: 4

page www of the periodical: www.phr.net.pl

Publisher

Polish Hyperbaric Medicine and Technology Society
Typ artykułu: oryginalny Original article

Submission date: $12.09 .2016 \mathrm{r}$.

Acceptance for print: 15.11.2016r. 


\section{INTRODUCTION}

Changes in the core body temperature are influenced by numerous factors, both endogenous, in the form of physiological and pathophysiological mechanisms, and exogenous. Circadian or infradian rhythms, or biological age are examples of endogenous factors [1].

Many authors report a strongly modulating influence of environmental factors on homoeostasis, including the hyperbaric environment. Depending on exposure time and type, a diver is exposed to various physical factors including, first of all, high hydrostatic pressure, physical and chemical effects of a respiratory agent, and low ambient temperatures.

Interfering agents associated with the effect of the hyperbaric environment on the human body include: the toxic effect of oxygen, the narcotic effect of inert gases, decompression sickness, the abnormal functioning of some sensory systems (in particular sight, somatosensory and vestibular systems), and hypothermia [2,3].

Effectively functioning regulation and adaptation mechanisms in the divers body should counterbalance the effects of stress agents associated with staying in hyperbaric conditions. In the available literature there are no reports on changes in the core body temperature occurring in a diver's body exposed to conditions in the hyperbaric chamber, i.e. excluding the influence of water temperature on thermoregulatory processes.

The aim of this study was to analyse dynamic fluctuations in the circadian rhythm of the core body temperature in healthy adults exposed to conditions in a hyperbaric chamber, using objective and modern measurement methods.

\section{MATERIAL AND METHODS}

\section{Study group}

The study group consisted of 13 healthy men. Apart from giving a voluntary informed consent to participation in the study, the main enrolment criteria included being of the male sex, an absence of diseases and the possession of the correct body mass (BMI: 18.5- 24.99 $\mathrm{kg} / \mathrm{m}^{2}$ ). Exclusion criteria included: an active or chronic disease and taking any medicines throughout the study. The basic biological parameters of the studied group are characterised in Table 1.

\begin{tabular}{ll}
\hline \multirow{2}{*}{ Parameter } & Studied group $(\mathrm{n}=\mathbf{1 3})$ \\
\cline { 2 - 2 } & mean $\mathbf{S}$ SD \\
\hline Age, years & $32 \pm 6.4$ \\
\hline Body height $[\mathrm{cm}]$ & $179 \pm 8.7$ \\
\hline Body weight, $[\mathrm{kg}]$ & $83.4 \pm 14.7$ \\
\hline BMI, $\left[\mathrm{kg} / \mathrm{m}^{2}\right]$ & $25.9 \pm 3.5$ \\
\hline
\end{tabular}

Vital Sense - telemetric measurements of the core body temperature

In the subjects the core body temperature (CBT) was measured with the Vital Sense telemetry system from Mini Mitter, currently Philips Respironics (Vital Sense, Mini Mitter Co. Inc., Bend Oregon, USA). The system consists of two components: a mobile recording display storing and exporting digital data for measured temperature values, and a telemetric capsule - Core Body Temperature Capsule (CBTC) (Fig. 1).

The telemetric capsule transmits the measured core body temperature values by radio. The telemetric system consists of an internal thermistor and of an external cover made of plastic adapted to medical applications. A study subject swallows the capsule with a small amount of warm water. After approximately one minute the capsule starts measuring the body's core temperature and emitting a radio signal at 15 second intervals; the display saves an average value of four successive measurements. The registered and transmitted values of the core temperature are saved in the display's internal memory. The telemetric capsule is resistant to digestive enzymes, and excreted without any side effects or effect on the gastrointestinal tract function.
The volunteers were placed in a hyperbaric chamber and exposed to a compression of $400 \mathrm{kPa}$. The exposure plateau was equal to approx. 30 minutes, and followed by gradual decompression in accordance with the decompression tables of the Polish Navy (Table 2).

For safety reasons, to minimise the risk of side effects - "bends", the decompression pattern used following the exposure to $400 \mathrm{kPa}(0.4 \mathrm{MPa}-0.3 \mathrm{MPa}+0.1$ $\mathrm{MPa}$ atmospheric pressure) was the same as after diving at 33 meters, which corresponds to the pressure of 440 $\mathrm{kPa}$. Air was the breathing gas used during all dives in the hyperbaric chamber.

Exposure characteristics 
Decompression chamber following exposure at $30 \mathrm{~m}$ below sea level (bsl)

\begin{tabular}{ccccc}
\hline Exposure (m bsl) & Plateau (min.) & Decompression stop depth (m) & Overall \\
& & Time at a decompression stop (min.) & $\begin{array}{l}\text { decompression } \\
\text { duration }\end{array}$ \\
\hline 33 & 30 & 9 & 6 & 35 minutes \\
\hline
\end{tabular}

Study protocol

To evaluate the effect of the hyperbaric environment on the core body temperature, a continuous monitoring of the core body temperature was started before subjects entered the hyperbaric chamber, and continued during one hour of exposure and for the following 24 hours (Fig. 1, 2).

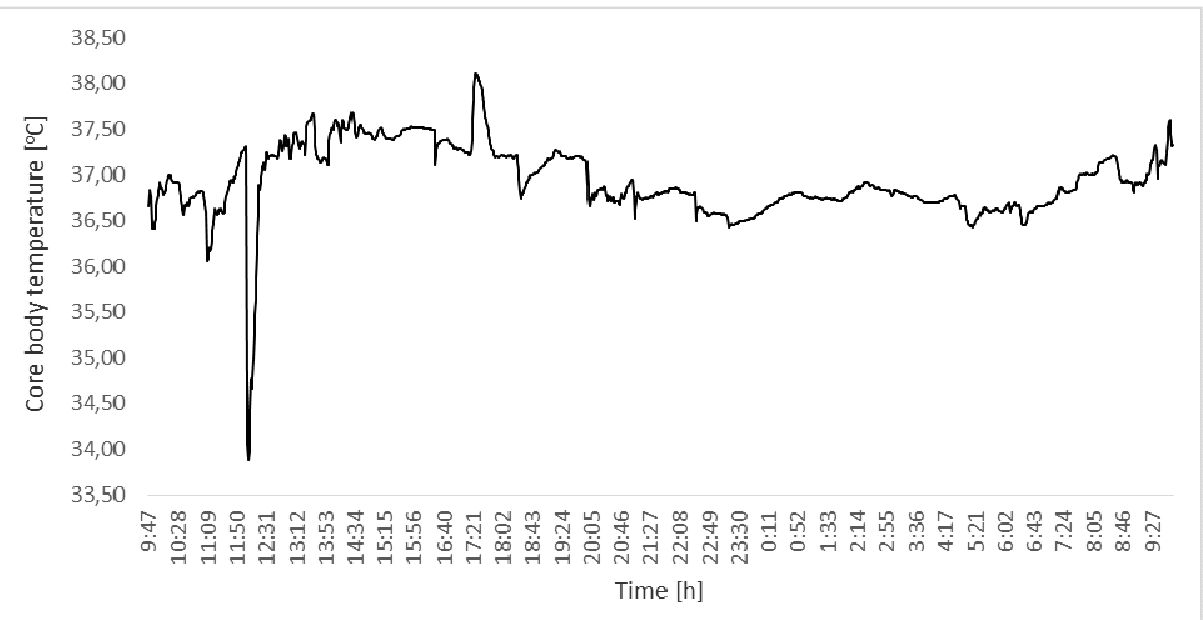

Fig. 1. An example of a 24 hour recording of the core body temperature in a diver exposed to conditions of the hyperbaric chamber.

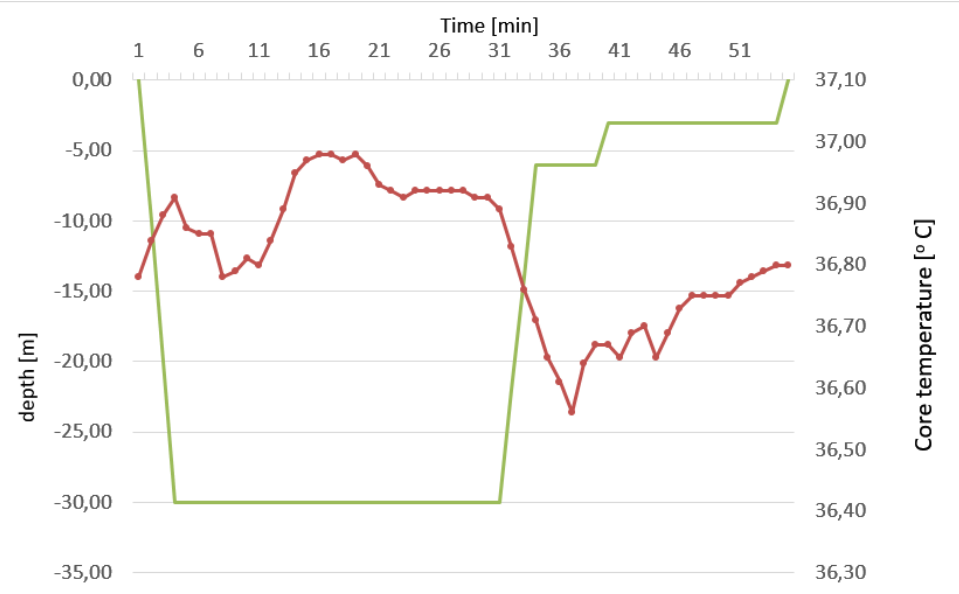

—depth $[\mathrm{m}] \quad$ - Core temperature $\left[{ }^{\circ} \mathrm{C}\right]$

Fig. 2. An example of a recording of the core body temperature in a diver during exposure. 
To obtain a detailed analysis of the dynamics of core temperature fluctuations, and avoid errors resulting from possible single and occasional anomalies appearing during temperature measurements, a specific form of analysis of core temperature measurements was applied. Signals obtained throughout the study were divided into 15-minute measurement intervals, for which the mean averages of measured core temperature were calculated and then analysed statistically.

For the purpose of this publication, a statistical analysis of 16 measurement intervals was presented (MI_01-MI_16), corresponding to: MI_01 - measurement taken 10 minutes prior to the exposure, MI_02-MI_05 during the exposure, MI_06-MI_09 - one hour after the exposure, MI_10-MI_13 - 2 hours after the exposure, and MI_14-MI_16 - 3 hours after the exposure.

\section{Statistical methods}

The normality of variabilities distribution was evaluated with the Shapiro-Wilk test, and their statistical characteristics were presented as arithmetic means and standard deviations $( \pm \mathrm{SD})$, as well as calculated minimum and maximum values. The results were analysed using the Friedman's test and Kendall rank correlation. All calculations were performed with the Statistica 10 (StatSoft) package, with the assumed level of statistical significance of $\alpha<0.05$.

\section{RESULTS}

Values of the core body temperature obtained during exposure to the hyperbaric environment are presented in Table 3 (MI - measurement interval). The mean core temperature was $36.71{ }^{\circ} \mathrm{C}$, when registered within 10 minutes before the exposure, $37.20^{\circ} \mathrm{C}$ during the exposure, $37.27^{\circ} \mathrm{C}$ one hour after the exposure, $37.36^{\circ} \mathrm{C}$ two hours after the exposure, and $37.42^{\circ} \mathrm{C}$ three hours after the exposure.

\begin{tabular}{|c|c|c|c|c|c|}
\hline & $\mathbf{N}$ & Mean & Minimum & Maximum & $\begin{array}{l}\text { Standard } \\
\text { deviation }\end{array}$ \\
\hline MI_01 & 13 & 36,92 & 36,71 & 37,20 & 0,15 \\
\hline MI_02 & 13 & 37,00 & 36,70 & 37,61 & 0,22 \\
\hline MI_03 & 13 & 37,13 & 36,69 & 37,77 & 0,27 \\
\hline MI_04 & 13 & 37,18 & 36,73 & 37,58 & 0,23 \\
\hline MI_05 & 13 & 37,24 & 36,76 & 37,66 & 0,25 \\
\hline MI_06 & 13 & 37,25 & 36,80 & 37,69 & 0,24 \\
\hline MI_07 & 13 & 37,24 & 36,76 & 37,73 & 0,26 \\
\hline MI_08 & 13 & 37,30 & 36,93 & 37,72 & 0,21 \\
\hline MI_09 & 13 & 37,28 & 36,93 & 37,72 & 0,23 \\
\hline MI_10 & 13 & 37,32 & 37,02 & 37,72 & 0,18 \\
\hline MI_11 & 13 & 37,37 & 37,10 & 37,73 & 0,18 \\
\hline MI_12 & 13 & 37,36 & 37,12 & 37,74 & 0,17 \\
\hline MI_13 & 13 & 37,38 & 37,12 & 37,71 & 0,16 \\
\hline MI_14 & 13 & 37,42 & 37,20 & 37,69 & 0,13 \\
\hline MI_15 & 13 & 37,42 & 37,17 & 37,68 & 0,17 \\
\hline MI_16 & 13 & 37,43 & 37,07 & 37,64 & 0,18 \\
\hline
\end{tabular}


Absolute differences between mean MI_01 ranks and other measurement intervals (rank differences $>6.59$, at the confidence level of $<0.05$, were marked as *).

\begin{tabular}{|c|c|}
\hline $\begin{array}{l}\text { Measurement } \\
\text { interval }\end{array}$ & MI_01 \\
\hline MI_01 & --- \\
\hline MI_02 & 1,77 \\
\hline MI_03 & 2,69 \\
\hline MI_04 & 4,69 \\
\hline MI_05 & 5,61 \\
\hline MI_06 & 5,96 \\
\hline MI_07 & 6,04 \\
\hline MI_08 & $8,04^{*}$ \\
\hline MI_09 & $7,58^{*}$ \\
\hline MI_10 & $8,54^{*}$ \\
\hline MI_11 & $10,15^{*}$ \\
\hline MI_12 & $9,88^{*}$ \\
\hline MI_13 & $10,58^{*}$ \\
\hline MI_14 & $11,38^{*}$ \\
\hline MI_15 & $10,69 *$ \\
\hline MI_16 & $10,23^{*}$ \\
\hline
\end{tabular}

During the study, significant differences in the core body temperature were noted between MI_01 and MI_08, MI_09, MI_10, MI_11, MI_12, MI_13, MI_14, MI_15, MI_16 (Table 3).

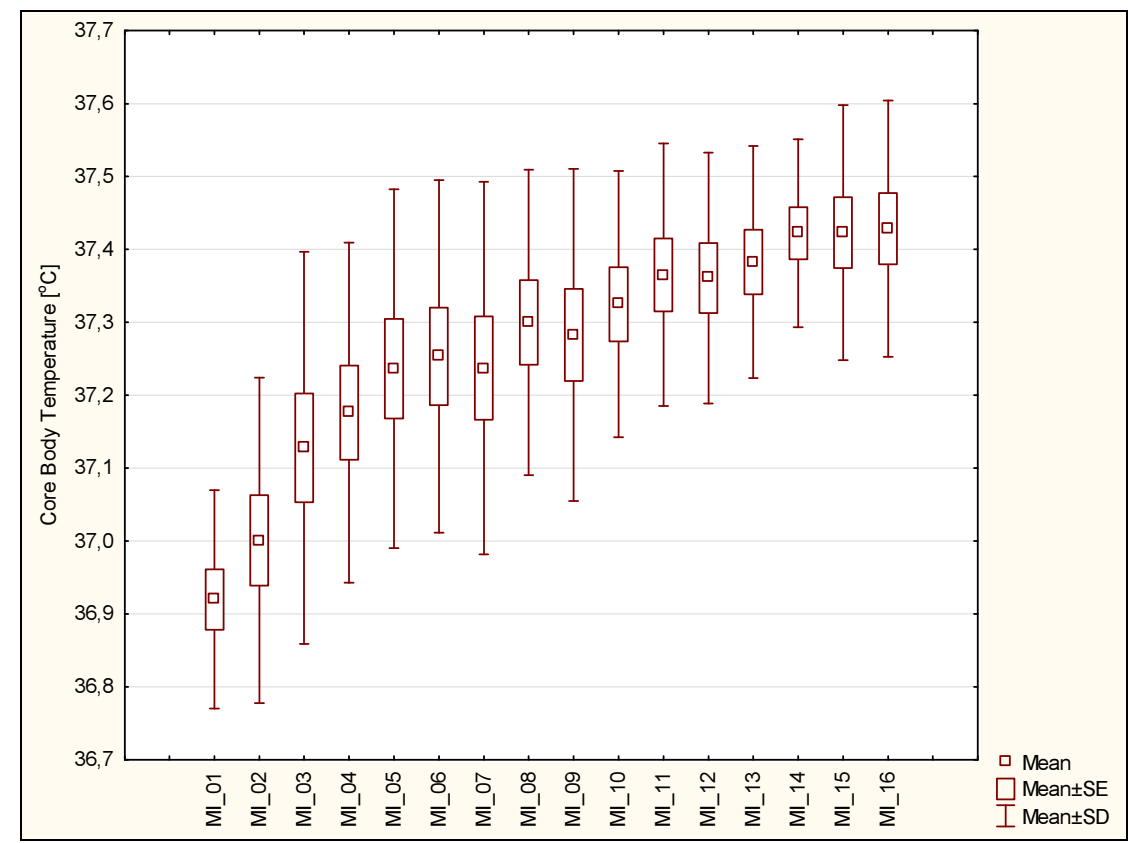

Fig. 3. Recorded changes in the core body temperature for each measurement interval. 


\section{DisCuSSION}

Exposure to the hyperbaric environment changes the circadian rhythm of the core body temperature. The conducted observations show that a one-hour stay in a hyperbaric chamber at a depth of 30 $m$ results in an increase in body temperature, particularly significant after the exposure ends, and is maintained for at least 3 hours after the exposure.

When the body adapts to the increased pressure in its environment, the core body temperature rises, resulting in an increased blood flow to tissues, facilitating gas exchange during the first phase of diving, the stay at $30 \mathrm{~m}$ bsl and removal of excessive amounts of gases when returning to normobaric conditions.

As the highest absorption of inert gases occurs during the first (and usually the deepest) stage of diving, this mechanism may significantly increase tissue perfusion. Ultimately, it may pose a risk of decompression disease during diving. Studies on repeated diving were conducted on Vancouver Island in British Columbia [4]. The divers wore wet suits, both well and poorly suited to the conditions. The water temperature was approx. $10^{\circ} \mathrm{C}$.

Using a Doppler ultrasound transducer, the researchers measured the presence and number of gas bubbles in the divers' blood. They observed lower levels of bubbles in divers dressed unsuitably. The researchers concluded that when a diver is cold before diving, constriction of blood vessels hinders blood flow in their limbs, resulting in turn in a limited absorption of inert gases. A lower absorption of inert gases led to their lower levels at the end of diving.

Previously, the available reports described the effect of water temperature on disrupted thermoregulation in divers. With decreasing water temperature, metabolic processes increase proportionally to a drop both in the core body and in skin surface temperature. In cold water vasoconstriction in the skin is triggered by a decrease in skin surface temperature. However, a drop in the core body temperature influences an increase in the activity of the sympathetic nervous system, resulting in vasoconstriction during prolonged exposure to cold $[5,6]$.

\section{BIBLIOGRAPHY}

1. Someren EJW, Raymann RJEM, Scherder EJA, Daanen HAM, Swabb DF: Circadian and age-related modulation of thermoreception and temperature regulation: mechanisms and functional implications. Ageing Research Reviews 2002; 1, 721- 778;

2. Buzzacott P, Denoble PJ, Simon O, Dunford R, Vann RD: Dive problems and risk factors for diving morbidity. Diving Hyperb Med, 2009. 39(4): p. 205-9;

3. Perovic A, Unic A, Dumic J: Recreational scuba diving: negative or positive effects of oxidative and cardiovascular stress? Biochem Med (Zagreb), 2014. 24(2): p. 235-47. DOI: 10.11613/BM.2014.026;

4. Mekjavic IB, Kakitsuba N: Effect of peripheral temperature on the formation of venous gas bubbles. Undersea Biomed Res 1989; 16(5): 391-401;

5. Pendergast DR, Lundgren CEG: The underwater environment: cardiopulmonary, thermal, and energetic demands. J Appl Physiol 2009. 106: 276-283. DOI: 10.1152/japplphysiol.90984.2008;

6. Pendergast DR: The effect of body cooling on oxygen transport during exercise. Med Sci Sports Exerc 20, Suppl: S171-S176, 1988;

7. Sramek P, Simeckova M, Jansky L, Savlikova J, Vybiral S: Human physiological responses to immersion into water of different temperatures. Eur J Appl Physiol. 2000 Mar;81(5):436-42;

8. Simon E: Nitric oxide as a peripheral and central mediator in temperature regulation. Amino Acids 14: 87-93, 1998;

9. Matsuda M, Nakayama H, Arita H, Morlock JF, Claybaugh J, Smith RM, Hong SK: Physiological responses to head-out immersion in water at 11 ATA. Undersea Biomed Res. 1978 Mar;5(1):37-52. 
Joanna Słomko

Katedra Higieny, Epidemiologii i Ergonomii CM UMK ul. M. Sklodowskiej-Curie 9

85-094 Bydgoszcz

E-mail: jslomko@cm.umk.pl 